\title{
Patterns of Caffeinated Energy Drinks Consumption among Adolescents and Adults in Hail, Saudi Arabia
}

\author{
Mo'ez Al-Islam Ezzat Faris ${ }^{1,2}$ \\ ${ }^{1}$ Department of Clinical Nutrition, College of Applied Medical Sciences, University of Hail, Hail, KSA; ${ }^{2}$ Department of Nutrition, \\ Faculty of Pharmacy and Medical Sciences, Petra University, Amman, Jordan. \\ Email: moezfaris@hotmail.com
}

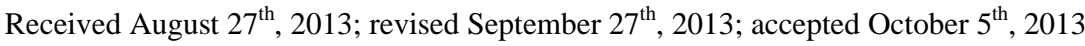

Copyright (C) 2014 Mo’ez Al-Islam Ezzat Faris. This is an open access article distributed under the Creative Commons Attribution License, which permits unrestricted use, distribution, and reproduction in any medium, provided the original work is properly cited. In accordance of the Creative Commons Attribution License all Copyrights (C) 2014 are reserved for SCIRP and the owner of the intellectual property Mo’ez Al-Islam Ezzat Faris. All Copyright (c) 2014 are guarded by law and by SCIRP as a guardian.

\section{ABSTRACT}

Caffeinated energy drinks have become more popular in the last decades, especially amongst adolescents and young adults in different parts of the globe. The study aims to investigate the frequency of energy-drink consumption and associated factors in an arbitrary group of adults and adolescents living in Hail/Saudi Arabia. A cross-sectional study was conducted and included which randomly selected 1062 participants (867 males and 195 females) from universities, colleges, middle-to-higher schools and social settings. Data collection was conducted using a self-administered standard tested questionnaire. The current study revealed about $46 \%$ had drunk energy drinks, while about $54 \%$ did not ever drink energy drinks. Out of the energy drinks consumers, $37 \%$ started drinking during the primary school, $64 \%$ consumed energy drinks on a daily basis, and $44 \%$ consumed two or more cans per day. Reasons behind not taking energy drinks were the belief that they are unhealthy drinks (about two-thirds of non-drinkers), and lack of curiosity for energy drinks (18\%). Other reasons such as unaccepted taste, thought to be obesogenic, and the possibility of getting addicted were also reported. From all participants, only $23 \%$ and $4 \%$ knew about the presence of caffeine and taurine, respectively, in energy drinks. Unreliable resources were the major sources of knowledge about energy drinks and their health effects. Awareness of community about the ingredients and potential hazards of energy drinks should be raised and encouraged by designing and implementing educational programs.

\section{KEYWORDS}

\section{Energy Drinks; Knowledge; Adults and Adolescents; Saudi Arabia}

\section{Introduction}

Energy drinks are caffeinated beverages designed to enhance alertness and provide a burst of energy. Caffeine is the principal pharmaceutical and bioactive ingredient in energy drinks, in addition to B vitamins, taurine or L-carnitine, and herbal extracts such as Ginkgo biloba or ginseng, and may or may not contain high doses of sugar or a sugar substitute [1].

Recently, consumption of energy drinks has become popular amongst adolescents and young adults in different parts of the world. This popularity may principally be ascribed to the massive marketing strategies directed toward this target that people and strategies focus on the psychoactive and stimulant properties of these beverages $[2,3]$. Accordingly, it has been reported that young adults and college students consume energy drinks more frequently than others [4-6]. While athletes were the primary market targets for the energy drink producers, it had been shown that young adults and adolescents between 16 - 35 years of age became the primary target $[4,7,8]$.

Factually, the consumption of moderate amounts of caffeine had been reported to attain a list of positive cognitive, physical and muscular impacts including increase in alertness, wakefulness, and feel of energy, the ability to solve problems, decreasing mental and muscular fatigue, and enhancing physical, motor and cognitive performances and short-term memory $[9,10]$. However, nu- 
merous reports have been published on the toxicity and health hazards of energy drinks, with health effects ranging from mild to severe, complicated states and even death $[11,12]$ among which reported by adolescents are dizziness, inability to focus, difficulty in concentration, nervousness, gastrointestinal upset and insomnia, in addition to other effects such as anxiety, seizures, accelerated heart rates, dehydration, acute mania and even strokes $[3,12,13]$. Nevertheless, harms of energy drinks are not limited to physiological hazards, but also extended to be accompanied with behavioral problems such as sexual risk-taking, fighting, not using seatbelts, and also associated with smoking, drinking alcohol, and illicit prescription drug use amongst adult college students [5].

Owing to their unregulated and frequently containing high amounts of caffeine, energy drink consumption was found to be associated with serious adverse effects, especially in children, adolescents, and young adults with diabetes, cardiac abnormalities and behavioral disorders [14]. Following heavy consumption of energy drinks, discrete seizures on multiple occasions were reported in four 19 - 28 years adults, with a complete absence of the seizures once the patients were abstinent from the energy drinks [15]. Further, a young adolescent boy presented with sinus tachycardia and high blood pressure was reported because of the regular consumption of energy drinks during examination period [16].

Studies on the consumption of energy drinks in Saudi Arabia are scarce, despite the obviously noticed consumption of these drinks in different community settings. This notice was reinforced by the Global Energy Drinks Report (2012) [17], which unraveled that Saudi Arabia was ranked among the top ten countries with the consumption of energy drinks. Amongst the limited studies, a study conducted on secondary school girls in a western province showed that $52.2 \%$ of the 600 interviewed girls had tried energy drinks [18]. In the middle provinces, the majority (66\%) of 1719 intermediate and secondary school male and female students had never taken energy drinks [19]. While, in the eastern region, results derived from 412 college students showed that $54.60 \%$ of males and $26.15 \%$ of females were energy drink consumers [20].

Hail province, northern of the Saudi Arabia, is with more than 750 thousand residents distributed over about 103 thousands $\mathrm{Km}^{2}$. According to the available literature, no studies have been published concerning the prevalence of energy drink consumption in Hail province. Therefore, the current study aimed at investigating the prevalence of consumption of energy drinks amongst adults and adolescents in Hail city, and finding out the socio-economic and behavioral factors associated with energy drink consumption, and the knowledge about energy drinks acquired by the study participants.

\section{Materials and Methods}

\subsection{Study Design and Objectives}

The study is mainly descriptive in nature, with an ultimate objective of screening the intended groups of people for energy-drink consumption and related behaviors and lifestyle factors. The study was primarily intended to estimate the consumption rates among college and high school students. Due to socio-cultural constraints, the inclusion of female subjects in the current study was limited due to the social segregation between males and females in the community settings at Hail city.

A structured and validated questionnaire of 33 questions was introduced for the study of subjects, after the objectives of the study were elaborated for the respondents. The structured questionnaire used in the current study was built upon a previously utilized pre-tested questionnaire developed by Attila and Cakir (2011) [21]. However, different modifications were introduced on the questionnaire to be more suitable for and compatible with the Saudi society regarding the demographic, economic and socio-cultural aspects of life, including sexual behavior, alcohol consumption, type of housing, income levels and health insurance, and factors related to taking or not taking energy drinks. These modifications were introduced during the process of validating the questionnaire.

\subsection{Data Collection}

A total of 1062 subjects (867 males and 195 females) from different age groups were enrolled in the study. Data collection was performed over the period from February 2013 to June 2013. Verbal consent was received from each participant. Participation was voluntary and no incentives were provided to participants. A short and brief explanation on the energy drinks was introduced to each participant, and examples on brand names of energy drinks available in the local market were provided in order not to be confused with common soda, colas or sport drinks available in the same local markets.

\subsection{Statistical Analysis}

Statistical analysis includes frequency and percentages of distributions. The status of knowledge on energy drink ingredients and the source of knowledge about energy drinks were tested among all study participants. An exploratory analysis was performed by SPSS (version 17) to model significant predictors of energy-drink consumption (users vs. non-users). Gender (male vs. female), marital status (married, single, divorced vs. widowed), job (student, employee, housewives vs. retired), income (low vs. high), monthly expenditure (low vs. high), sleeping 
pattern (regular vs. irregular), monthly income source (self-dependent, dependent vs. other sources), smoking status (smokers vs. nonsmokers), physical activity (regular vs. irregular), and breakfast eating (regular vs. irregular) were checked for their potential associations with energy consumption because these were the factors identified in previous studies as potential confounders or as being associated with energy-drink consumption.

\section{Results}

The distribution of socio-demographic characteristics of study participants was shown in Table 1 . The vast majority (about $82 \%$ ) of the study participants were males, with females represented less than fifth $(18 \%)$ of the study population. The majority of the study participants were young adults (80\%) with age range from 18 - 40 years, followed by the adolescents (12 - 17 years) (about $16 \%$; thus the adolescents and young adults of the school and college ages representing about $96 \%$ of the study participants. Educational level for the study participants was middle and secondary school for $59 \%$ of the participants, and college level for $35 \%$ of the participants. Nuclear family represents the type of family for the most of the study participants (76\%), followed by the extended family type and those who live alone or with friends in dormitory represented $2.3 \%$ of the participants. High educational level for the parents of the study participants were about 34 and $44 \%$ for fathers and mothers, respectively.

The economic level for more than half of the study population was high, more than 10,000 SAR ( $\$ 2670$ / month). Students were asked to report the average monthly income that they usually spend for their personal needs and privates expenses rather than official fees and governmental expenses. More than half of the study population reported monthly personal expenditure of less than 1000 SAR (\$267). As the majority of the study population was school and college students, more than half of the participants were dependent on others (parents or guardians).

Personal daily habits of the study participants that may be associated with using energy drinks were reported in Table 2. As it is shown in the table, regular and irregular sleeping patterns were near to be similar (about half to half), with more than half of the study participants had sleep duration of 6 - 8 hours. About one-third (33\%) of the study participants were currently smokers, with cigarette smoking was the most commonly used smoking tool for more than two-thirds (64\%) of them. Not using the safety belt while driving or being in a car was reported by about $38 \%$ of the study participants, with about quarter of the participants drove car very fast. In Hail, and many parts of Saudi Arabia, middle and secondary school students,
Table 1. Distribution of sociodemographic characteristics of study participants.

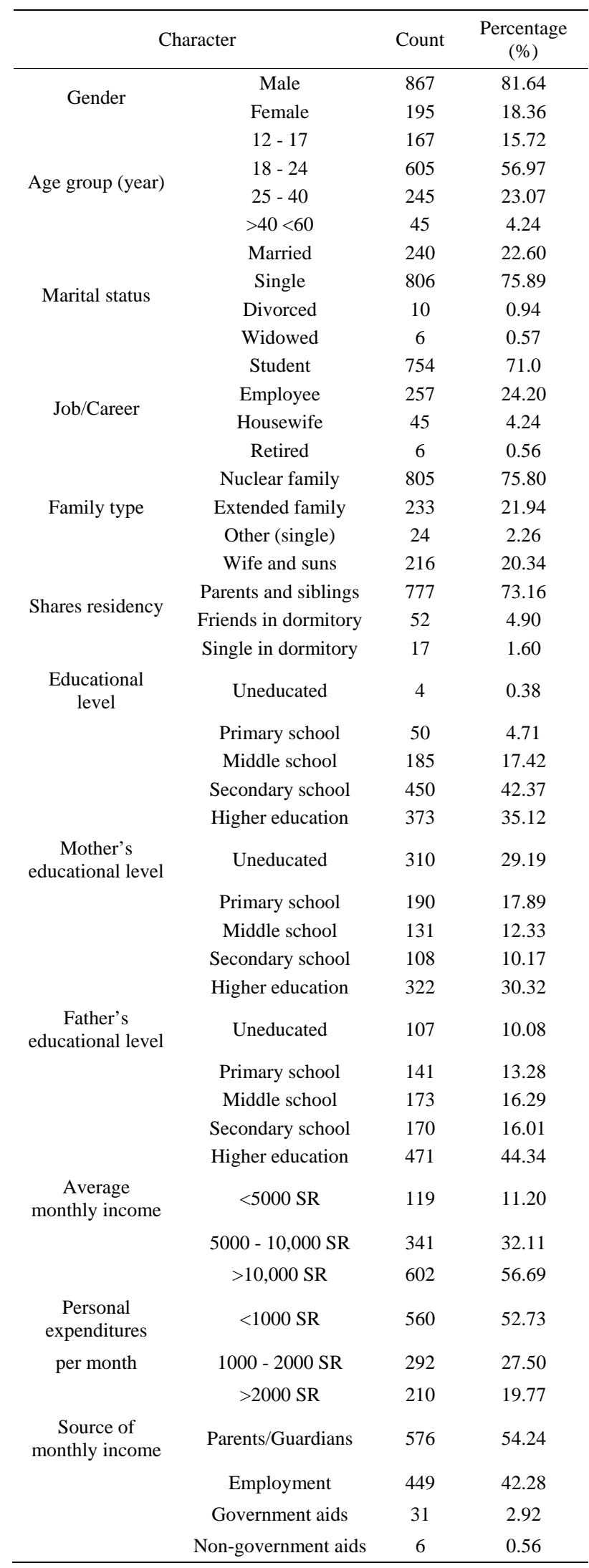


Table 2. Distribution of personal daily habits among the study participants.

\begin{tabular}{|c|c|c|c|}
\hline Habit & & Count & Percentage \\
\hline \multirow{2}{*}{ Nature of sleeping } & Regular & 541 & 50.94 \\
\hline & Irregular & 521 & 49.06 \\
\hline \multirow{3}{*}{ Sleeping hours } & $<6 \mathrm{hr}$ & 348 & 32.77 \\
\hline & $6-8 \mathrm{hr}$ & 562 & 52.92 \\
\hline & $>8 \mathrm{hr}$ & 152 & 14.31 \\
\hline \multirow{3}{*}{ Smoking status } & Non-smoker & 627 & 59.04 \\
\hline & Previous smoker (non-smoker now) & 88 & 8.29 \\
\hline & Smoker now & 347 & 32.67 \\
\hline \multirow{3}{*}{$\begin{array}{l}\text { If smoking now, what type of } \\
\text { smoking? }(n=347)\end{array}$} & Cigarette & 223 & 64.26 \\
\hline & Nargile & 41 & 11.81 \\
\hline & Mixed (cigarette and nargile) & 83 & 23.93 \\
\hline \multirow{5}{*}{ Safety behaviors } & Not using safety belt while being in or riding a car & 405 & 38.14 \\
\hline & Driving car very fast & 250 & 23.54 \\
\hline & Carrying weapons and guns & 12 & 1.13 \\
\hline & Practicing violence or exposed to violence & 70 & 6.59 \\
\hline & None of the above & 325 & 30.60 \\
\hline \multirow{3}{*}{ Practicing physical exercises } & Regularly practiced & 169 & 15.91 \\
\hline & Not regularly practiced & 464 & 43.69 \\
\hline & Not practiced & 429 & 40.40 \\
\hline \multirow{3}{*}{ Eating breakfast meal } & Regular & 424 & 39.92 \\
\hline & Irregular & 511 & 48.12 \\
\hline & Never & 127 & 11.96 \\
\hline
\end{tabular}

as well as the college students usually drive cars while being studying in the school or college. About $84 \%$ of the study participants were not or irregularly practicing physical exercises, with about $60 \%$ were either not or irregularly eating breakfast.

Energy-drink use and its related behaviors among study participants are shown in Table 3 . According to the interviewed participants, about $46 \%$ answered "Yes" when were asked whether they are energy drink consumers or not. The major three factors behind using and not using energy drinks are illustrated in the Table 3.

For the energy drink consumers, the first experience was at home according to about one third (34\%), not remembered by about $20 \%$, and in recreation settings by $17 \%$. For the person who accompanied the energy drink consumer during his first trial, one-third of were accompanied by one of the family members, followed by colleagues or friends, while $25 \%$ did not remember. Regarding the timing and educational stage during which energy drinks were first tried, amazingly more than one third reported that it was during the primary school stage, $13 \%$ during the middle school, and $22 \%$ divided equally between two educational stages: before the primary school and during secondary school. For the most common periods during which energy drinks were drank, $50 \%$ reported there is no definite time period, $25 \%$ while driving their cars and $20 \%$ during vacations (Table 3 ).
Behaviors related to consumption of energy drinks among energy drink consumers are presented in Table 4. Of the 492 energy drink consumers, 314 (about 64\%) consume them on a daily basis; with varying number of energy drink cans were consumed each day. $36 \%$ of the daily consumers drink more than two cans every day, representing about $11 \%$ of the total study participants, while about one third of them consume two cans every day; accordingly, those who drink two or more energy drink cans every day represent more than two-thirds of the daily consumers, and about one-fifth (20\%) of the total study participants. Lastly, one third (about 32\%) of the daily consumers drink one or less of energy drink cans every day.

Regarding the relationship between timing of energy drink consumption and regular meals, $43 \%$ reported that they consume the drinks after meals, 35\% consume them regardless of the regular meals time, and $14 \%$ consume them with meals. When the participants were asked about the places where energy drinks are most commonly consumed, they reported while being in their cars (27\%), at homes $(26 \%)$, at recreation places (22\%) and in coffee shops (19\%).

When they were asked about the major physiological consequences being felt after consuming energy drinks, about 56\% answered "feeling activated and energized", and "reducing sleeping hours", while 15\% reported 
Table 3. Energy drinks use and its related behaviors among study participants.

\begin{tabular}{|c|c|c|c|}
\hline Energy drink-related behavior & & Count & Percentage \\
\hline \multirow{2}{*}{ Do you drink energy drinks? } & Yes & 492 & 46.33 \\
\hline & No & 570 & 53.67 \\
\hline \multirow{8}{*}{$\begin{array}{c}\text { If no, why? } \\
\text { (up to three major reasons) } \\
\text { (number of responses }=678 \text { ) }\end{array}$} & Have no curiosity to try it & 102 & 15.04 \\
\hline & I belief they are not healthy & 351 & 51.77 \\
\hline & Lack of knowledge about their composition & 37 & 5.46 \\
\hline & I'm active and no need for more activation & 23 & 3.39 \\
\hline & Expensive & 9 & 1.33 \\
\hline & May cause addiction & 8 & 1.18 \\
\hline & Do not like their taste & 42 & 6.19 \\
\hline & For religious considerations & 10 & 1.47 \\
\hline \multirow{8}{*}{ 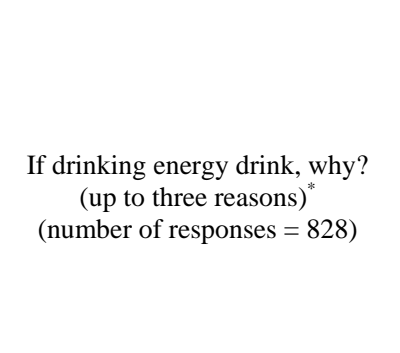 } & Like its taste & 273 & 32.97 \\
\hline & To be more active and energized & 281 & 33.95 \\
\hline & To improve my physical and mental activities & 109 & 13.16 \\
\hline & To mix it with other drinks & 26 & 3.15 \\
\hline & To be awake for longer time & 83 & 10.02 \\
\hline & To improve my academic and studying performance & 24 & 2.91 \\
\hline & To mimic others (famous persons, friends and colleagues) & 5 & 0.60 \\
\hline & To improve my sexual power & 7 & 0.84 \\
\hline \multirow{8}{*}{$\begin{array}{l}\text { Timing when first tried energy } \\
\text { drinks }(n=492)\end{array}$} & For courtesy and compliment with others & 20 & 2.4 \\
\hline & Before primary school & 53 & 10.77 \\
\hline & During primary school & 179 & 36.38 \\
\hline & During middle school & 62 & 12.60 \\
\hline & During university/college years & 33 & 6.71 \\
\hline & After graduation/during employment stage & 35 & 7.11 \\
\hline & Do not remember & 78 & 15.85 \\
\hline & In my home & 168 & 34.29 \\
\hline \multirow{6}{*}{$\begin{array}{l}\text { Place where the first trail of using } \\
\text { energy drinks was }(n=490)\end{array}$} & In recreational places & 83 & 16.94 \\
\hline & In the street & 80 & 16.33 \\
\hline & In the coffee shop & 32 & 6.53 \\
\hline & In the student dormitory & 3 & 0.61 \\
\hline & In other places & 18 & 3.67 \\
\hline & Do not remember & 106 & 21.63 \\
\hline \multirow{4}{*}{$\begin{array}{l}\text { Companion when first tried energy } \\
\text { drinks }(n=488)\end{array}$} & Friend or colleague & 139 & 28.48 \\
\hline & Family member & 145 & 29.71 \\
\hline & No body & 89 & 18.24 \\
\hline & Do not remember & 115 & 23.57 \\
\hline \multirow{10}{*}{$\begin{array}{l}\text { I know that energy drinks contain } \\
\text { (more than one answer allowed) }^{*} \\
\quad(\text { number of responses }=2570)\end{array}$} & Sugar & 691 & 26.89 \\
\hline & Caffeine & 584 & 22.72 \\
\hline & Water and minerals & 113 & 4.40 \\
\hline & Carbon dioxide and other gasses & 222 & 8.64 \\
\hline & Citric acid & 199 & 7.74 \\
\hline & Taurine & 93 & 3.62 \\
\hline & Protein & 113 & 4.40 \\
\hline & Alcohol (diethyl ether) & 213 & 8.29 \\
\hline & Nicotine & 124 & 4.82 \\
\hline & Hormones and activating substances & 218 & 8.48 \\
\hline
\end{tabular}




\begin{tabular}{|c|c|c|c|}
\hline \multirow{8}{*}{$\begin{array}{l}\text { Sources of knowledge about energy } \\
\text { drinks (up to three major sources) } \\
\text { (number of responses }=2236 \text { ) }\end{array}$} & Study/work colleagues & 471 & 21.06 \\
\hline & Friends and partners & 706 & 31.57 \\
\hline & Social networks and websites & 316 & 14.13 \\
\hline & Viewed mass media (TV) & 290 & 12.97 \\
\hline & Written media (newspapers and magazines) & 143 & 6.39 \\
\hline & General, non-scientific, websites & 118 & 5.28 \\
\hline & Scientific journals and academic books and websites & 65 & 2.91 \\
\hline & Food labels on energy drinks cans & 127 & 5.68 \\
\hline
\end{tabular}

*Due to multiple answer-questions, percentage is from the total number of responses not from total number of participants. Therefore, total number of responses may exceed the total number of drinker or non-drinker participants.

"changes in cardiac functioning and heart beating", and $10 \%$ reported that no beneficial physiological effect is gained after energy drink consumption. Other minor reported consequences (approx 17\%) were: hydrating the body and supporting it with water and electrolytes, causing addiction and inducing obesity, causing peptic ulcer and raising blood sugar, increase sexual tendency and capability, and causing depression and activating the brain while causing limbs apathy.

One of the main objectives of the current study was to assess the knowledge level of the study population on the composition of energy drinks. Only 23, 27 and 9\% of the study participants knew that caffeine, sugar and carbon dioxide and other gasses, respectively, are energy drink ingredients. Lower percentage of the participants (4\%) knew that minerals, taurine and protein are constituents of energy drinks. Amazingly, 8\% stated that energy drinks contain ethanol, recreational hormones and chemicals, and citric acid. The major sources of knowledge concerning the composition of energy drinks were from: friends and colleagues (32\%) school/college or work companions (21\%) electronic social networks (14\%); sighted mass media (13\%); and from scientific reliable resources such as academic book, scientific journals and electronic websites (3\%). Thus, non-reliable sources of knowledge on energy drink composition and health effects reported for $80 \%$ of the study population.

The final logistic regression model for energy-drink consumption by study participants (users or non-users) is presented in Table 5. The result shows that, regardless the age group, men were about four times more likely to consume energy drinks than women; monthly personal expenditure (low or high) appeared not to be a limiting factor in using energy drinks, and low or high monthly personal expenditure participants seemed to be similar in likely using the energy drinks. Low monthly income participants were more likely to use energy drinks than those with high income, and those who were self-dependent in their monthly income source were more likely to use energy drinks than those who were dependent on others; and finally those who practiced physical activity regu- larly were more likely to use energy drinks than those who practiced it irregularly.

\section{Discussion}

In the last decade, the consumption of energy drinks has grown exponentially, with aggressive advertising and marketing strategies primarily targeted youth and young adults $[2,3]$. This emphasizes the importance of conducting such a research to explore the extent to which the practice of energy drink consumption is popular and common in this area.

Different factors had been reported to trigger adults and adolescents to consume energy drinks, such as for being more active and energized, enjoying the taste, stay awake for a longer time, to improve the physical and mental activities; all were reported in the current research in variable degrees $[3,22,23]$.

Caffeine is the major principal active ingredient in the energy drinks or energy stimulants, with other psychoactive stimulant ingredients such as guarana and ginseng. The combined sources of caffeine in energy drinks, from added caffeine and from plant extracts, raise caffeine content to reach a level of 70 to $80 \mathrm{mg}$ per 8-oz serving. This concentration is 3-time more than that in cola drinks, and may reach 5 times in some types of energy drinks [14]. Glucose is added as the basic sweetener in energy drinks. The combination of caffeine and glucose can ameliorate deficits in cognitive performance and subjective fatigue during extended periods of cognitive demand. Therefore, energy drinks were found to improve attention and/or reaction times and indices of alertness [24,25], thus the positive effects of energy drinks could explain the widespread use of energy drinks amongst adolescents and adults in Saudi Arabia and other parts of the world.

Adolescents and young adults are often unaware, that various stimulant products, such as energy drinks, contain caffeine. When these products are taken regularly on a daily, adverse effects from caffeine toxicity and severe adverse medical impacts may be conferred [8].

Caffeine has been found to have adverse health consequences. Such effects had been associated with caffe- 
Table 4. Behaviors among energy drinks users.

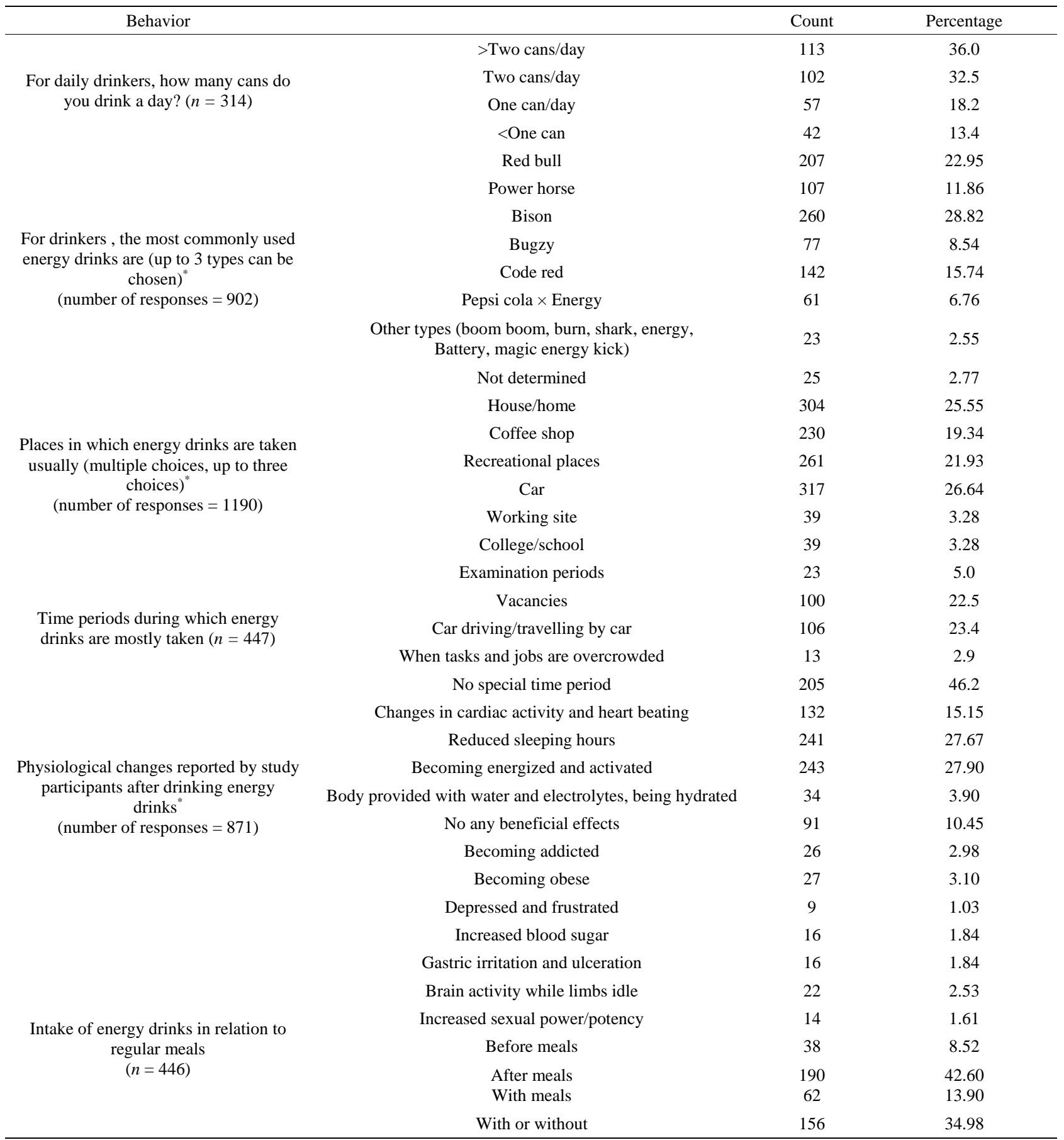

*Due to multiple answer-questions, percentage is from the total number of responses not from total participants. Therefore, total number of responses may exceed the total number of drinker or non-drinker participants.

ine consumption in amounts greater than $400 \mathrm{mg}$, and include sleeplessness, irritability, nervousness, dehydration and increased urination, stomach upset and arrhythmia, nausea, heart palpitations, ventricular and atrial tachycardias, headache, insomnia, anxiety, and irritability [26]. Further, acute caffeine consumption was found to reduce insulin sensitivity and increases mean arterial blood pressure, to be associated with chronic daily headaches, particularly among young women (age $<40$ years) and among those with chronic episodic headaches of recent onset. Wide spectrum of detrimental health consequences had been reported on varying body functioning including neural, cardiovascular, gastrointestinal, and renal dysfunctions when caffeine is ingested chronically 
Table 5. Logistic regression model for energy drinkers.

\begin{tabular}{cccccc}
\hline Variables in Model & Beta & SE & $P$ (Wald Test) & O.R. & $95.0 \%$ CI \\
\hline Gender (Male vs. Females) & 1.316 & 0.215 & 0.000 & 3.728 & $2.447-5.680$ \\
Married vs. Single/Divorced/Widowed & -0.526 & 0.264 & 0.046 & 0.591 & $0.353-0.991$ \\
Students vs. Others (Employees, Housewives/Retired) & -0.258 & 0.271 & 0.342 & 0.772 & $0.454-1.315$ \\
Income (Low vs. High) & 0.129 & 0.140 & 0.357 & 1.137 & $0.865-1.495$ \\
Monthly Expenditure (Low vs. High) & -0.087 & 0.221 & 0.693 & 0.916 & $0.594-1.414$ \\
Monthly Income Source (Self vs. Dependent) & 0.284 & 0.157 & 0.070 & 1.328 & $0.977-1.806$ \\
Sleep Patterns (Regular vs. Irregular) & -0.283 & 0.144 & 0.049 & 0.753 & $0.569-0.998$ \\
Smoking (Current Smokers vs. Nonsmokers) & -0.126 & 0.146 & 0.388 & 0.882 & $0.662-1.174$ \\
Physical Activity (Regular vs. Irregular) & 0.250 & 0.182 & 0.171 & 1.284 & $0.898-1.834$ \\
Eating Breakfast (Regular vs. Irregular) & -0.546 & 0.138 & 0.000 & 0.579 & $0.442-0.759$ \\
Constant & 0.725 & 0.948 & 0.445 & 2.064 & \\
\hline
\end{tabular}

*O.R.: Odd's Ratio; C.I: Confidence Interval.

$[27,28]$. However, the percentage of participants who reported their knowledge about the inclusion of caffeine in energy drinks was low in the current study.

In the current study, about $46 \%$ of the study participants were energy drink consumers. This value is comparable with the previously published reports among American college students (46\%) [29], near to that of another report published on Turkish college students (48.3\%) [21], less than that for college students in the United States (51\%) [30], and in Ghana (62.2\%) [6]. When comparing with results from Saudi Arabia, our obtained values were less than that reported in Western districts (52.2\%) [18], much higher than that reported in the Middle (34\%) [19], between those of male (54.6\%) and female (26\%) adult college students in the Eastern region [20].

Energy drinks consumption among Saudi adolescents was positively correlated with screen setting (TV and PC use), eating fast foods, sugar-sweetened beverages, French fries, potato chips, cake, donuts and sweets; while their consumption was negatively correlated to body mass index, eating breakfast meal, and consuming fruits, vegetables, and milk and dairyproducts [31]. Further, Al Hazzaa and coworkers demonstrated that overweight and obese Saudi adolescent females are significantly using energy drinks less frequently than males [32]. Further, similar finding was reported that Saudi adult males tend to consume more energy drinks than their counterpart females [32].

The principal three trademarks of energy drinks and most commonly consumed by energy drink users were presented in Table 4. Caffeine content for the first two most commonly consumed energy drinks in Saudi market was analyzed, and values of 238.0 and $345.5 \mathrm{mg} / \mathrm{L}$, respectively, were reported by Hassan and Al-Abbad (2011) [33].

Several reports have indicated a relationship between energy drink and sugar-sweetened soft drinks, and the increased incidence of obesity amongst children and adolescents [34,35]. In Saudi Arabia, incidence of obesity has been alarmingly increasing during the last two decades, with plausible association could be present with the dramatic increase in energy drink consumption [34,35]; a matter that requires more research and further clarification. In the current study, the obesogenic effect of energy drink consumption was one of the reasons behind not consuming energy drinks by the non-drinkers, and similarly was reported by the consumers as one of the physiological consequences for consuming such energy-dense drinks. This obesogenic effect of energy drinks was reported, whether, energy drinks are contributing to the obesity epidemic or not [36]. From healthy women 18 - 22 years of age, they found that consumption of energy drinks caused reduced lipid oxidation and increased carbohydrate oxidation, speculating that the combined high intakes of caffeine and table sugar from energy drinks may lead to obesity, especially when accompanied with sedentary lifestyle.

Several reports indicated that energy drinks are considered unhealthy, with varying health hazards and toxic effects could be attained [12,13]. However, some adolescent consumers use energy drinks for their perceived physiologic benefits and that they may not be aware of the potential risks [22]. Interestingly, in our study, the first reason behind not consuming energy drinks was that the non-consumers stated that they "belief they are not healthy" and they declared this as the major reason behind not trying energy drinks.

The physiological effect of consuming energy drinks on cardiac functioning was reported as the third main sensed effect, next to "being energized" and "reducing sleeping hours", a matter that indicates for a relatively good awareness toward the hazardous effect of energy drinks [23,27]. In the first study, in young adults 21 - 26 
years old, the hemodynamic effects of acute caffeine intake was found to affect heart rate after load up to 4.5 hours after consuming caffeine. In the second randomized, double-blind study, researchers found that acute caffeine consumption profoundly increases large artery waveform transmission and central blood pressure, and decreased pressure amplification in healthy adults.

A case study on a healthy 28-year-old man who had a cardiac arrest after an excessive consumption of energy drinks during a day of motocross racing was published [11]. The researchers postulated that a combination of excessive intakes of taurine- and caffeine-rich energy drinks, along with the extensive physical activity might induce coronary vasospasm leading to myocardial ischemia. In another study, the cardiac effects of a commercially available energy drinks were investigated [37]. It was also found that systolic blood pressure increased $10 \mathrm{mmHg}$ and heart rate increased 5 - 7 beats/min after energy drink consumption in 15 healthy volunteers. Further, changes in the electrocardiogram and heart rate were reported after intake of an energy drink, especially when taken in combination with alcohol and exercise [38].

The current study is the first study on the prevalence of energy drink consumption in the northern of Saudi Arabia, with relatively the larger number of participants amongst adolescents and young adults in comparison with many other relevant studies conducted in Saudi Arabia and in other countries. Nevertheless, the current study involved several limitations. Among these limitations: relatively small number of female subjects, relatively limited number of participants who could not give a real and representative picture for the whole study population of the kingdom of Saudi Arabia, and the inclusion of different age groups in the study makes it difficult to exclude the confounding factors that could arise from the uniqueness of each group alone.

\section{Conclusion}

From the previous findings, it can be concluded that energy drinks are consumed in relatively high rates amongst adolescents and adults, with different social and socio-economic factors affecting the consumption of such drinks, along with a partial lack of the scientific sound knowledge concerned with the composition and health implications of consuming these stimulant drinks. Educational and extensional programs should be designed and implemented at the community level to raise the level of awareness about these drinks and their health effects.

\section{Acknowledgements}

Dr. Epuru Suneetha kindly performed statistical analysis, and data collection was done with assistance from Mr. Fhaid Al-Aslamy. Thanks are due to my colleagues Dr. Mohammad Adnan, Dr. Tariq Osaily and Dr. Murad Al-Holy for their fruitful comments and revisions.

\section{REFERENCES}

[1] A. Peacock, F. H. Martin and A. Carr, "Energy Drink Ingredients. Contribution of Caffeine and Taurine to Performance Outcomes,” Appetite, Vol. 64, 2013, pp. 1-4. http://dx.doi.org/10.1016/j.appet.2012.12.021

[2] H. J. Smit and P. J. Rogers, "Effects of 'Energy' Drinks on Mood and Mental Performance: Critical Methodology," Food Quality and Preference, Vol. 13, No. 5, 2002, pp. 317-326. http://dx.doi.org/10.1016/S0950-3293(02)00044-7

[3] C. J. Reissig, E. C. Strain and R. R. Griffiths, "Caffeinated Energy Drinks. A Growing Problem,” Drug and Alcohol Dependence, Vol. 99, No. 1, 2009, pp. 1-10. http://dx.doi.org/10.1016/j.drugalcdep.2008.08.001

[4] K. M. Babu, R. J. Church and W. Lewander, "Energy Drinks: The New Eye-Opener for Adolescents,” Clinical Pediatric Emergency Medicine, Vol. 9, No. 1, 2008, pp. 35-42. http://dx.doi.org/10.1016/j.cpem.2007.12.002

[5] K. E. Miller, "Energy Drinks, Race, and Problem Behaviors among College Students," Journal of Adolescent Health, Vol. 43, No. 5, 2008, pp. 490-497. http://dx.doi.org/10.1016/j.jadohealth.2008.03.003

[6] C. Buxton and J. E. Hagan, "A Survey of Energy Drinks Consumption Practices among Student-Athletes in Ghana: Lessons for Developing Health Education Intervention Programs," Journal of the International Society of Sports Nutrition, Vol. 9, No. 1, 2012, p. 9. http://dx.doi.org/10.1016/j.jadohealth.2008.03.003

[7] K. E. Miller, "Energy Drinks, Jock Identity, Masculine Norms, and Risk Taking," Journal of American College Health, Vol. 56, No. 5, 2008, pp. 481-489. http://dx.doi.org/10.3200/JACH.56.5.481-490

[8] H. Bunting, A. Baggett and J. Grigor, "Adolescent and Young Adult Perceptions of Caffeinated Energy Drinks: A Qualitative Approach,” Appetite, Vol. 65, 2013, pp. 132-138. http://dx.doi.org/10.1016/j.appet.2013.02.011

[9] M. A. Heckman, K. Sherry and E. G. de Mejia, "Energy Drinks: An Assessment of Their Market Size, Consumer Demographics, Ingredient Profile, Functionality, and Regulations in the United States," Comprehensive Reviews in Food Science and Food Safety, Vol. 9, No. 3, 2010, pp. 303-317. http://dx.doi.org/10.1111/j.1541-4337.2010.00111.x

[10] M. J. Glade, “Caffeine-Not Just a Stimulant,” Nutrition, Vol. 26, No. 10, 2010, pp. 932-938. http://dx.doi.org/10.1016/j.nut.2010.08.004

[11] A. J. Berger and K. Alford, "Cardiac Arrest in a Young Man Following Excess Consumption of Caffeinated 'Energy Drinks',” Medical Journal of Australia, Vol. 190, No. 1, 2009, pp. 41-43.

[12] N. Gunja and J. A. Brown, "Energy Drinks: Health Risks and Toxicity," Medical Journal of Australia, Vol. 196, 
No. 1, 2012, pp. 46-49. http://dx.doi.org/10.5694/mja11.10838

[13] N. Pennington, M. Johnson, E. Delaney and M. B. Blankenship, "Energy Drinks: A New Health Hazard for Adolescents," The Journal of School Nursing, Vol. 26, No. 5, 2010, pp. 352-359. http://dx.doi.org/10.1177/1059840510374188

[14] S. M. Seifert, J. L. Schaechter, E. R. Hershorin and S. E. Lipshultz, "Health Effects of Energy Drinks on Children, Adolescents, and Young Adults,” Pediatrics, Vol. 127, No. 3, 2011, pp. 511-528. http://dx.doi.org/10.1542/peds.2009-3592

[15] S. J. P. Iyadurai and S. S. Chung, "New-Onset Seizures in Adults: Possible Association with Consumption of Popular Energy Drinks,” Epilepsy \& Behavior, Vol. 10, No. 3, 2007, pp. 504-508. http://dx.doi.org/10.1016/j.yebeh.2007.01.009

[16] A. Usman and A. Jawaid, "Hypertension in a Young Boy: An Energy Drink Effect,” BMC Research Notes, Vol. 5, No. 1, 2012, p. 591. http://dx.doi.org/10.1186/1756-0500-5-591

[17] “Global Energy Drinks Report 2012,” 2013. http://www.researchandmarkets.com/reports/2105825/glo bal_energy_drinks report_2012

[18] R. Aluqmany, U. Mansoor, R. Saad, R. Abdullah and A. Ahamd, "Consumption of Energy Drinks among Female Secondary School Students, Almadinah Almunawwarah, Kingdom of Saudi Arabia,” Journal of Taibah University Medical Sciences, Vol. 8, No. 1, 2013, pp. 60-65. http://dx.doi.org/10.1016/j.jtumed.2013.01.009

[19] F. Al Buhairan, H. Tamim, W. Tamimi, S. Al Shahri, I. Al Alwan, M. E. Magzoub, N. E. Ahmed and M. Al Dubayee, "Dietary Patterns and Weight Status of Saudi Arabian Adolescents,” Journal of Adolescent Health, Vol. 50, No. 2, 2012, pp. S59-S60. http://dx.doi.org/10.1016/j.jadohealth.2011.10.160

[20] A. A. Alsunni and A. Badar, "Energy Drinks Consumption Pattern, Perceived Benefits and Associated Adverse Effects amongst Students of University of Dammam, Saudi Arabia," Journal of Ayub Medical College Abbottabad, Vol. 23, No. 3, 2011, pp. 3-9.

[21] S. Attila and B. Cakir, "Energy-Drink Consumption in College Students and Associated Factors," Nutrition, Vol. 27, No. 3, 2011, pp. 316-322. http://dx.doi.org/10.1016/j.nut.2010.02.008

[22] J. A. O'Dea, “Consumption of Nutritional Supplements among Adolescents: Usage and Perceived Benefits,” Health Education Research, Vol. 18, No. 1, 2003, pp. 98-107. http://dx.doi.org/10.1093/her/18.1.98

[23] A. M. Bender, R. L. Donnerstein, R. A. Samson, D. Zhu and S. J. Goldberg, "Hemodynamic Effects of Acute Caffeine Ingestion in Young Adults," American Journal of Cardiology, Vol. 79, No. 5, 1997, pp. 696-699. http://dx.doi.org/10.1016/S0002-9149(96)00848-X

[24] A. B. Scholey and D. O. Kennedy, "Cognitive and Physiological Effects of an 'Energy Drink': An Evaluation of the Whole Drink and of Glucose, Caffeine and Herbal Flavouring Fractions,” Psychopharmacology, Vol. 176, No. 3-4, 2004, pp. 320-330. http://dx.doi.org/10.1007/s00213-004-1935-2

[25] G. E. Giles, C. R. Mahoney, T. T. Brunyé, A. L. Gardony, H. A. Taylor and R. B. Kanarek, "Differential Cognitive Effects of Energy Drink Ingredients: Caffeine, Taurine, and Glucose,” Pharmacology Biochemistry and Behavior, Vol. 102, No. 4, 2012, pp. 569-577.

http://dx.doi.org/10.1016/j.pbb.2012.07.004

[26] M. Rath, "Energy Drinks: What Is All the Hype? The Dangers of Energy Drink Consumption," Journal of the American Academy of Nurse Practitioners, Vol. 24, No. 2, 2012, pp. 70-76. http://dx.doi.org/10.1111/j.1745-7599.2011.00689.x

[27] W. S. Waring, J. Goudsmit, J. Marwick, D. J. Webb and S. R. J. Maxwell, “Acute Caffeine Intake Influences Central More Than Peripheral Blood Pressure in Young Adults," American Journal of Hypertension, Vol. 16, No. 11, 2003, pp. 919-924.

http://dx.doi.org/10.1016/S0895-7061(03)01014-8

[28] A. A. Alsunni, “Are Energy Drinks Physiological?” $\mathrm{Pa}$ kistan Journal of Physiology, Vol. 7, No. 1, 2011, pp. 4449.

[29] C. Banda, A. Marietta, G. Syler and W. Hoover, "College Students' Knowledge, Attitudes and Behaviors Related to Energy Drinks," Journal of the American Dietetic Association, Vol. 110, No. 9, 2010, p. A108. http://dx.doi.org/10.1016/j.jada.2010.06.407

[30] B. M. Malinauskas, V. G. Aeby, R. F. Overton, T. C. Aeby and K. Barber-Heidal, "A Survey of Energy Drink Consumption Patterns among College Students," Nutrition Journal, Vol. 6, No. 1, 2007, pp. 35-41. http://dx.doi.org/10.1186/1475-2891-6-35

[31] H. M. Al Hazzaa, N. A. Abahussain, H. I. Al-Sobaye, D. M. Qahwaji and A. O. Musaiger, "Physical Activity, Sedentary Behaviors and Dietary Habits among Saudi Adolescents Relative to Age, Gender and Region,” International Journal of Behavioral Nutrition and Physical Activity, Vol. 8, No. 1, 2011, p. 140.

http://dx.doi.org/10.1186/1479-5868-8-140

[32] H. M. Al Hazzaa, N. A. Abahussain, H. I. Al-Sobaye, D. M. Qahwaji and A. O. Musaiger, "Lifestyle Factors Associated with Overweight and Obesity among Saudi Adolescents,” BMC Public Health, Vol. 12, No. 1, 2012, p. 354. http://dx.doi.org/10.1186/1471-2458-12-354

[33] M. I. Hassan and N. A. Al-Abbad, "Glutamate and Caffeine Intake of Some Snacks and Drinks in Saudi Arabia," Food and Nutrition Sciences, Vol. 2, No. 2, 2011, pp. 162-167. http://dx.doi.org/10.4236/fns.2011.22023

[34] S. Gibson, "Sugar-Sweetened Soft Drinks and Obesity: A Systematic Review of the Evidence from Observational Studies and Interventions,” Nutrition Research Reviews, Vol. 21, No. 2, 2008, pp. 134-147. http://dx.doi.org/10.1017/S0954422408110976

[35] J. Salmon, K. J. Campbell and D. A. Crawford, “Television Viewing Habits Associated with Obesity Risk Factors: A Survey of Melbourne Schoolchildren,” Medical Journal of Australia, Vol. 184, No. 2, 2006, pp. 64-67.

[36] E. Rush, S. Schulz, V. Obolonkin, D. Simmons and L. Plank, "Are Energy Drinks Contributing to the Obesity Epidemic?” Asian Pacific Journal of Clinical Nutrition, 
Vol. 15, No. 2, 2006, pp. 242-244.

[37] L. Steinke, D. E. Lanfear, V. Dhanapal and J. S. Kalus, “Effect of 'Energy Drink' Consumption on Hemodynamic and Electrocardiographic Parameters in Healthy Young Adults,” The Annals of Pharmacotherapy, Vol. 43, No. 4, 2009, pp. 596-602.

http://dx.doi.org/10.1345/aph.1L614
[38] U. Wiklund, M. Karlsson, M. Ostrom and T. Messner, "Influence of Energy Drinks and Alcohol on Post-Exercise Heart Rate Recovery and Heart Rate Variability," Clinical Physiology and Functional Imaging, Vol. 29, No. 1, 2009, pp. 74-80.

http://dx.doi.org/10.1111/j.1475-097X.2008.00837.x 